\title{
Energy \& Fuels Research in South African Universities: A Comparative Assessment
}

\author{
Anastassios Pouris*
}

Director: Institute for Technological Innovation, University of Pretoria, Hatfield, Pretoria, South Africa

\begin{abstract}
This article reports the results of a mapping and comparative assessment exercise of the field of energy \& fuels research in South African higher education institutions. Even though assessment of research activities is recognised as the cornerstone of science and technology policy in the country this is the first assessment of this field. The article identifies the most prolific countries and institutions in the world engaged in energy related research and it compares South Africa's energy research during the most recent ten years (1997-2007) with those of Australia, Canada, New Zealand and Malaysia according to a number of indicators (e.g. number of energy \& fuels publications per million population and number of publications per KWh of electricity produced). A number of policy implications for the country's science system in general and universities in particular are identified and are discussed.
\end{abstract}

Keywords: Energy research; policy; South Africa; indicators; universities.

\section{INTRODUCTION}

Disciplinary assessments are used internationally as benchmarks for the identification of effectiveness of policy instruments, for the support and justification of funding to political authorities, for identification of international collaborators, establishment of centres of excellence and so on.

In South Africa assessment of research activities is recognised as the cornerstone of science and technology policy. The National Advisory Council on Innovation in its recent submission to the Organisation of Economic Cooperation and Development (OECD) [1] states: "An outstanding characteristic of the National System of Innovation over the past decade has been the fact that almost all aspects are reviewed on a regular basis and following standard international practice".

On that basis a number of South African related assessments have appeared in the open and grey literature recently. [2-4].

Disciplinary assessments based on quantitative indicators are used internationally in support of policy development [58]. Although there is a number of different approaches that can be used for assessment purposes [9], there is a growing awareness of the advantages of basing opinions and subsequent choices on criteria that lend themselves more to quantitative evaluation. Science policy reviews would seem inconceivable today without recourse to existing indicators [10].

Indicators based on research publications are probably the most often used in the assessment of research activities. The philosophy underlying the use of research publications

*Address correspondence to this author at the Director: Institute for Technological Innovation, University of Pretoria, Hatfield, Pretoria, South Africa, Tel: +27124205178; Fax: +27123625092;

E-mail: Anastassios.pouris@up.ac.za as performance measures has been summarized in De Solla Price's statement that "for those who are working at the research front, publication is not just an indicator but, in a very strong sense, the end product of their creative effort" [11]. Consequently identifying the foot-prints of researchers can lead to mapping and assessing the research expertise and activities undertaken by a country, an institution and/or an individual. Of course there may be a large number of individuals with knowledge and experience in the particular field who do not undertake research and they do not publish. These people may apply their knowledge of the particular field; may teach or administer activities relevant to their knowledge. However, if they do not publish they are not researchers in the research front.

Quantitative assessments have a number of advantages. For example, they are repeatable and verifiable exercises. They are not dependent on the choice of experts and their opinions which may vary as the choice of the participants changes. Probably their most important advantage is that they allow comparisons among different scientific disciplines and different countries. Both types of comparisons are not possible through peer review approaches as it is almost impossible to find peers with expertise in different scientific fields and knowledge of the research systems in different countries.

Assessment of the field of "energy research" faces particular difficulties. The difficulties arise from the fact that energy research is not a coherent, well defined field of research. The definition used by the US Department of Energy is illustrative: "Energy research covers all research activities in the area of production, conservation, distribution and rational use of all forms of energy and the administration, economics, policy and planning of energy" [12]. Furthermore, energy research can be classified as interdisciplinary in character. That is, resolution of energy challenges requires knowledge, approaches and solutions from other scientific domains such as engineering, life and environmental sci- 
ences, economics and others. The diversity of the scientific disciplines contributing to energy research makes the boundaries of the field fuzzy.

A brief literature search for energy assessments identifies that the majority of the relevant literature has been produced during the eighties [13-17]. More recent contributions include those by Tijssen [18], Vanleeuwen [19], Uzun [20], and Kostoff et al. [21].

In South Africa limited mapping and comparative assessment exercises in the field of energy exist. This lack of research activity may have a number of adverse consequences for the economy. For example, it can be argued that the lack of expertise and independent advice (e.g. in the country's Universities) may be partially the cause of the recent failure of ESKOM to meet electricity demand in the country. (ESKOM is the only electricity supplier in South Africa).

The need for policy assessment and mapping of the energy field is further underpinned by the number of efforts to enhance and grow the field of energy in the country (e.g. pebble bed modular reactor (PBMR); research chairs; institutionalisation of energy research through the South African National Energy Research Institute (SANERI) etc). For example, knowledge of the current disciplinary focus in the field of energy in conjunction with the country's planned activities could facilitate the development of relevant priorities.

The objective of this investigation is to cover the identified gap by mapping and assessing energy research in South Africa. More specifically the objective is to assess the country's research performance in the field of energy over time, in comparison to other disciplines in the country and in comparison with a number of comparator countries. Additional questions that will be answered include: which are the main disciplines contributing to South African energy research? And which are the main centres of expertise in the country?

\section{METHODOLOGY}

Following international best practice, evaluative scientometrics for the objectives of this investigation are used. Scientometrics is a tool by which the state of science and technology can be observed through the overall production of scientific literature, at a given level of specialization. It is a means for situating a country in relation to the world, an institution in relation to a country and even individual scientists in relation to their own communities. Scientometric indicators are equally suitable for macro-analysis (e.g. a given country's share in global output of scientific literature over a specified period) and micro-studies (e.g. a given institute's role in producing articles in a particular field of science). They constitute a way to assess the current state of science, which in turn can help shed light on its structure.

A prerequisite for any scientometric analysis is the existence of an appropriate database. There are a number of specialized databases (e.g. Chemical Abstracts covering physics and chemistry; Compendex covering engineering and technology; Embase covering medical sciences, etc.) The energy field is covered by a number of databases such as the Energy Technology Data Exchange (ETDE) energy databases of the
International Energy Agency, the Energy Science and Technology (ESD) Database of the Government Research Centre in the USA and others. However these databases cannot be used for scientometrics purposes as their coverage is not homogeneous - in the ETDE database different governments contribute different types of data or no data at all and the ESD database contains monographs, theses; books and articles - and/or the incorporated in the database documents are not examined for quality. Furthermore not all databases include all authors' addresses - an element necessary in order to distribute research to different countries - and so on, eg. Compendex provides only the first author's affiliation which means that articles can be distributed to countries only according to first author and of course identification of collaboration is not possible.

The multidisciplinary and interdisciplinary character of energy research dictates that the information platform to be used for the identification of the relevant research articles should be multidisciplinary, multi-publisher and geographically diverse. An additional requirement is that the databases should include the addresses of all co-authors (and not only of the first author) in order to permit identification of collaborative patterns and in order to identify all articles with a South African co-author and not only those with a South African first author. These requirements will further permit comparisons of the South African performance with the performance of a number of comparator countries.

The Institute for Scientific Information (ISI) family of databases is commonly used as information platform for these types of analyses and assessments. The ISI family includes the following databases; Science Citation Index Expanded indexing 5,900 major journals; Social Sciences Citation Index indexing fully more than 1,725 journals and selected relevant items from over 3,300 of the world's leading scientific and technical journals; Arts and Humanities Citation Index covering fully 1,144 of the world's leading arts and humanities journals and individually selected, relevant items from over 6,800 major science and social science journals.

The combined databases cover comprehensively the most prestigious journals in the world in all fields of research endeavours and constitute a unique information platform for the objectives of this effort. The most important advantage of the ISI journals is that they constitute the most important (in terms of impact) journals in the world. Hence papers of no or marginal value are not included. All journals indexed by ISI are peer-reviewed. As a group, the ISI indexed set of journals represents an elite body of internationally influential research publications, but it does not represent a comprehensive cataloguing of the entire world's research journals, nor of all peer- reviewed journals.

ISI's intention is to index that part of the journal literature that exerts a disproportionate influence. The principle involved in this coverage strategy is based on the wellknown concept in bibliometrics, Bradford's Law of Scattering [22]. Bradford's Law asserts that a relatively small group of journals will account for the large majority of important and influential research in a given field. Bradford's assertion is that an essential core of journals forms the literature basis for all disciplines, and that, most of the important papers are 
published in relatively few journals. Researchers internationally aim firstly to publish their important research in the core journals of their field and only subsequently consider journals in the periphery. Recent citation analyses have shown that as few as 150 journals account for half of what is cited and one quarter of what is published. It has also been shown that a core of approximately 2,000 journals now accounts for $95 \%$ of cited articles [23]. ISI's philosophy is based in Bradford's Law [24].

In South Africa the Department of Education has identified the ISI indexed journals for subsidy purposes and Universities give incentives to their researchers to publish in ISIindexed journals. Consequently it is expected that the databases will cover the most important South African energy research as well.

The identified platform is interrogated for the identification of South African authors publishing in the field of "energy" during the last ten years. Two approaches were considered for the extraction of the relevant research literature phrase-based query and journal-title-based query. For the objectives of this investigation the journal-title-based query is considered as more appropriate. ISI assign the journals covered to scientific categories. The energy related journals are grouped under the title "energy and fuels." The group includes 62 journals. These 62 journals can be considered as consisting the "core" journals of the field of energy in the Bradfordian sense. As discussed, there are articles related to energy that are not published in the core journals. However, the most important and highest impact energy literature will be that published in the core journals and hence this analysis aims to identify South Africa's contribution in the core energy literature.

The extracted information is analyzed in order to identify trends over time, relative performance in comparison to other scientific disciplines in the country (e.g. nanotechnology); centres of expertise; co-authorship patterns with other countries and institutions and relative performance vis-à-vis a set of comparator countries (i.e. Malaysia, Australia, Canada, New Zealand). The comparator countries were chosen among those used for benchmarking exercises by the South African Department of Science and Technology.

\section{ENERGY RESEARCH IN SOUTH AFRICA}

Analysis of the core energy literature identified that 238 publications with at least one South African address appeared in the database during the 1997-2007 (April) period. This number constitutes $0.45 \%$ of the 52,265 South African publications in the ISI databases. Table 1 compares the number of publications produced during the period in the field of "energy and fuels" with those of other specialities. It shows the revealed priorities in SA and certain fields which are government priorities (e.g. astronomy, biotechnology, etc.) While specificities of different specialities may affect the comparison it becomes apparent that South Africa's research efforts focus on medicine, plant sciences, ecology, animals and the environment. Certain specialities specifically identified as research priorities by the Government (e.g. palaeontology, nanoscience and nanotechnology) appear to attract little attention in the field of research.
Table 1. Number of and Share in Country's Publications in Core Journals: SA Selected Fields 1997-2007

\begin{tabular}{|c|c|c|}
\hline Scientific Specialty & No Publications & \% of 52,265 \\
\hline \hline Medicine, General \& Internal & 3160 & 6.04 \\
\hline Plant Sciences & 2651 & 5.07 \\
\hline Ecology & 1832 & 3.50 \\
\hline Zoology & 1417 & 2.71 \\
\hline Environmental Sciences & 1300 & 2.48 \\
\hline Veterinary Sciences & 1169 & 2.23 \\
\hline Infectious Diseases & 1130 & 2.16 \\
\hline Astronomy and Astrophysics & 1089 & 2.08 \\
\hline Water Resources & 1063 & 2.03 \\
\hline Biotechnology \& Applied Micro- & 908 & 1.73 \\
\hline biology & 414 & 0.79 \\
\hline Oceanography & 238 & 0.45 \\
\hline Energy and Fuels & 152 & 0.29 \\
\hline Palaeontology & 79 & 0.15 \\
\hline Nanoscience and Nanotechnology & & \\
\hline & & \\
\hline
\end{tabular}

Although there are a number of factors (e.g. industrial orientation; international influences; culture etc) defining what may be called national revealed priorities (disciplines or specialities with above average publications) it can be argued that in South Africa disciplines for which research support has been institutionalised in the country (e.g. plant and animal sciences through the Agricultural Research Council; medicine through the Medical Research Council; water resources through the Water Research Commission) define research priorities and determine the country's research outputs.

Table 2 shows the number of South African publications in the core energy literature for the period 1997-2007 per year. It becomes apparent that South Africa's contribution to core energy literature is in an increasing trend. The number of South African publications, albeit from a low level, has doubled from 22 during 2001 to 43 during 2006.

Table 2. Number of SA energy publications 1997-2007

\begin{tabular}{|c|c|c|}
\hline Publication Year & Record Count & \% of 238 \\
\hline \hline $2007 *$ & 9 & 3.78 \\
\hline 2006 & 43 & 18.06 \\
\hline 2005 & 41 & 17.22 \\
\hline 2004 & 21 & 8.82 \\
\hline 2003 & 27 & 11.34 \\
\hline 2002 & 15 & 6.30 \\
\hline 2001 & 22 & 9.24 \\
\hline 2000 & 17 & 7.14 \\
\hline 1999 & 17 & 7.14 \\
\hline 1998 & 15 & 6.30 \\
\hline 1997 & 11 & 4.62 \\
\hline$* 2007$ data until end March & & \\
\hline
\end{tabular}

* 2007 data until end March 
Table 3. Distribution of SA Energy \& Fuels Literature to Scientific Specialities

\begin{tabular}{|c|c|c|}
\hline Subject Category & Record Count & $\%$ of 238 \\
\hline Engineering, Chemical & 63 & 26.47 \\
\hline Thermodynamics & 49 & 20.58 \\
\hline Mechanics & 27 & 11.34 \\
\hline Engineering, Mechanical & 26 & 10.92 \\
\hline Agricultural Engineering & 20 & 8.40 \\
\hline $\begin{array}{l}\text { Biotechnology \& Applied Microbiol- } \\
\text { ogy }\end{array}$ & 20 & 8.40 \\
\hline Engineering, Petroleum & 20 & 8.40 \\
\hline Environmental Sciences & 20 & 8.40 \\
\hline Environmental Studies & 19 & 7.98 \\
\hline Materials Science, Multidisciplinary & 17 & 7.14 \\
\hline Engineering, Electrical \& Electronics & 15 & 6.30 \\
\hline Nuclear Science \& Technology & 9 & 3.78 \\
\hline Physics, Nuclear & 8 & 3.33 \\
\hline Engineering, Civil & 7 & 2.94 \\
\hline Electrochemistry & 6 & 2.52 \\
\hline $\begin{array}{c}\text { Applied Construction \& Building } \\
\text { Technology }\end{array}$ & 5 & 2.10 \\
\hline Geosciences, Multidisciplinary & 4 & 1.68 \\
\hline Engineering, Multidisciplinary & 4 & 1.68 \\
\hline Engineering, Ocean & 3 & 1.26 \\
\hline Water Resource & 3 & 1.26 \\
\hline Chemistry, physical & 2 & 0.84 \\
\hline Mining \& Mineral Processing & 2 & 0.84 \\
\hline $\begin{array}{c}\text { Physics, Atomic, Molecular \& } \\
\text { Chemical }\end{array}$ & 2 & 0.84 \\
\hline Economics & 1 & 0.42 \\
\hline Physics, Applied & 1 & 0.42 \\
\hline
\end{tabular}

Table 3 shows the distribution of the South African "energy and fuels" publications to different scientific specialities. Articles are allocated to categories according to journal in which they are published. Journals are categorised by the ISI staff and they may belong to one or more categories. Chemical engineering and thermodynamics are the top scientific disciplines contributing $26.47 \%$ and $20.58 \%$ respectively in the field of energy and fuels. South Africa's contribution in the core "energy \& fuels" literature appears to be focused on engineering and other technological issues (e.g. thermodynamics, mechanics and so on). Environmental sciences and environmental studies contribute only $16.38 \%$ in the energy \& fuels literature.
Table 4 shows the major South African organisations (six or more publications over the period) of core energy \& fuels literature. The Universities of Cape Town and Pretoria are sharing the top position contributing $11.76 \%$ of the relevant literature each (28 publications).

SASOL, RAU and University of Stellenbosch follow with above $10 \%$ contributions. It is worth mentioned the participation of an industrial establishment like SASOL in the country's scientific endeavours, as it is not a common phenomenon in South Africa. (SASOL is one of Africa's major producers of chemicals and liquid fuel products and a key player in the SA oil industry.) Other businesses appearing in the database (albeit with an even smaller number of appearances) are: ESKOM (3); SOEKOR PTY LTD (3); Honeywell Hi-Spec Solutions (3); National Petroleum Refiners of South Africa (Natref) (3); SAPPI (2); Willard Batteries (2) and others.

Table 4. Producers of South African Energy \& Fuels Literature

\begin{tabular}{|c|c|c|}
\hline Institution Name* & Record Count & \% of 238 \\
\hline \hline University of Cape Town & 28 & 11.76 \\
\hline University of Pretoria & 28 & 11.76 \\
\hline SASOL & 27 & 11.34 \\
\hline Rand Afrikaans University & 26 & 10.92 \\
\hline University of Stellenbosch & 24 & 10.08 \\
\hline University of Witwatersrand & 16 & 6.72 \\
\hline University of Natal & 10 & 4.20 \\
\hline Potchefstroom University of Chris- \\
tian Higher Education & 9 & 3.78 \\
\hline University of Port Elizabeth & 9 & 3.78 \\
\hline CSIR & 7 & 2.94 \\
\hline Tshwane University of Technology & 6 & 2.52 \\
\hline
\end{tabular}

* Since 2004 the South African academic landscape is in a transition period with a number of institutions having being merged. In this table the names are retained as they appear in the various publications. Publications under the name Kwa-Zulu Natal have been amalgamated in the University of Natal; this may have inflated marginally the number of publication from Natal if the publications under the name Kwa-Zulu Natal were the result of researchers previously belonging to University of Durban Westville. Different SASOL divisions have been amalgamated under the name SASOL.

The top five institutions in the table participate in the production of just above $50 \%$ of the country's contribution to core energy \& fuels literature. This is a considerable dispersion as a number of other scientific disciplines are concentrated in one or two institutions in the country. For example, in the field of veterinary medicine/animal health the University of Pretoria produces $61.68 \%$ of the country's research publications. The University is producing $49.15 \%$ of the country's publications in metallurgy and $46.96 \%$ in engineering mathematics. The same phenomenon has been noticed in the analysis of nano-scale research in the country [25]. It appears that political equity considerations in the 
country spill-over in the research domain as well. The issue is of particular developmental and science policy importance. Can a country leap-frog its science and innovation system to catch up the rest of the world and compete internationally through a "distributed" approach or it should concentrate its limited scientific expertise to a limited, focused research centres?

It should be emphasised that the shown performance of the South African academic institutions (20 publications over a ten year period - i.e. two publications per year) is grossly sub-critical. One or two researchers in a University could easily produce that performance that whole institutions produce currently. A caveat that should be kept in mind is that the small number of publications produced makes the stability of the comparison over time sensitive to the movement of researchers from one institution to another. For example the move of one or two prolific researchers from one institution to another could drastically change the rankings of the institutions producing energy research.

Table 5 shows the energy specialisation of the country's top four most prolific academic institutions - University of Cape Town (UCT); University of Pretoria (UP); Rand Afrikaans University (RAU) and University of Stellenbosch. The tables show that the revealed priorities vary from institution to institution. At UCT emphasis is on environmental issues of energy; at the University of Pretoria on chemical engineering and thermodynamics; at RAU on material sciencesmulti-disciplinary and at the University of Stellenbosch on mechanical engineering. The "high" concentration of publications in specific disciplines is the result of limited number of researchers working in the field of energy in different institutions.

Table 5. Disciplinary Emphasis of Universities

\begin{tabular}{|c|ll|}
\hline University & \multicolumn{2}{|c|}{ Top Disciplines Emphasised \% } \\
\hline \hline University of Cape & Environmental Sciences & $50.0 \%$ \\
Town & Environmental Studies & $50.0 \%$ \\
\hline \multirow{2}{*}{ University of Pretoria } & Thermodynamics & $50.0 \%$ \\
& Engineering, Chemical & $46.4 \%$ \\
\hline Rand Afrikaans Uni- & Materials Science, Mult. & $38.4 \%$ \\
versity & Thermodynamics & $38.4 \%$ \\
\hline University of Stel- & Engineering, Mechanical & $66.6 \%$ \\
lenbosch & Thermodynamics & $41.6 \%$ \\
\hline
\end{tabular}

Table 6 shows the countries with which South African researchers collaborate for their research in the field of energy and fuels. Just above ten percent of relevant publications are co-authored with researchers from the USA. England and Germany follow with seven and six record counts respectively.

Analysis of the disciplinary emphasis of the country's collaboration with the USA shows that the country's collaboration is focused primarily on environmental issues and secondarily in engineering: electrical \& electronics.
Table 6. International collaboration of South Africa

\begin{tabular}{|c|c|c|}
\hline Country/Territory & Record Count & \% of 238 \\
\hline \hline USA & 25 & 10.50 \\
\hline England & 7 & 2.94 \\
\hline Germany & 6 & 2.52 \\
\hline France & 5 & 2.10 \\
\hline India & 5 & 2.10 \\
\hline Netherlands & 5 & 2.10 \\
\hline Canada & 4 & 1.68 \\
\hline Australia & 3 & 1.26 \\
\hline Spain & 3 & 1.26 \\
\hline
\end{tabular}

\section{SOUTH AFRICAN ENERGY RESEARCH IN THE IN- TERNATIONAL CONTEXT}

In order to set South Africa's energy research in an international context, a snap-shot of the world energy literature and comparison of South Africa with four comparator countries is provided.

Table 7 shows the countries which have produced above $1 \%$ of the world's energy literature during the 2000-2006 period. During the period the core energy \& fuels journals published 56,005 articles. Of these the USA has produced 9,694 articles which constitute $17.3 \%$ of the total output. Japan and Peoples Republic of China follow contributing above $5 \%$ each. South Africa is contributing $0.34 \%$ of the relevant literature.

Table 7. Energy Research Producing Countries 2000-2006

\begin{tabular}{|c|c|c|}
\hline Country/Territory & Record Count & \% of 56,005 \\
\hline \hline USA & 9,694 & 17.3092 \\
\hline Japan & 3,183 & 5.6834 \\
\hline Peoples R of China & 2,995 & 5.3477 \\
\hline Canada & 2,329 & 4.1586 \\
\hline England & 2,198 & 3.9246 \\
\hline Germany & 1,939 & 3.4622 \\
\hline France & 1,848 & 3.2997 \\
\hline Russia & 1,669 & 2.9801 \\
\hline India & 1,663 & 2.9694 \\
\hline Turkey & 1,647 & 2.9408 \\
\hline Spain & 1,324 & 2.3641 \\
\hline South Korea & 1,197 & 2.1373 \\
\hline Australia & 1,087 & 1.9409 \\
\hline Italy & 1,000 & 1.7856 \\
\hline Sweden & 794 & 1.4177 \\
\hline Taiwan & 710 & 1.2677 \\
\hline Netherlands & 682 & 1.2177 \\
\hline Brazil & 641 & 1.1445 \\
\hline Greece & 616 & 1.0999 \\
\hline Mexico & 588 & 1.0499 \\
\hline
\end{tabular}


Table 8 shows the most prolific institutions in the world (having produced more than 200 publications over the period) in the field of energy research. The Russian Academy of Sciences appears in the top position with 813 records. The Chinese Academy of Science and the Indian Institute of Technology follow with 416 and 394 publications respectively.

Table 8. Prolific Energy Research Organisations

\begin{tabular}{|c|c|c|}
\hline Institution Name & Record Count & $\%$ of 56005 \\
\hline Russian Acad Sci & 813 & 1.4517 \\
\hline Chinese Acad Sci & 416 & 0.7428 \\
\hline Indian Inst Techn & 394 & 0.7035 \\
\hline CSIC & 288 & 0.5142 \\
\hline Tsing Hua Univ & 285 & 0.5089 \\
\hline Sandia Natl Labs & 262 & 0.4678 \\
\hline Penn State Univ & 259 & 0.4625 \\
\hline CNRS & 248 & 0.4428 \\
\hline Shanghai Jiao Tong Univ & 248 & 0.4428 \\
\hline Tohoku Univ & 246 & 0.4392 \\
\hline Natl Inst Adv Ind Sci \& Tech & 240 & 0.4285 \\
\hline Univ Calif Berkeley & 228 & 0.4071 \\
\hline Inst Francais Petr & 216 & 0.3857 \\
\hline Univ Calgary & 216 & 0.3857 \\
\hline $\begin{array}{l}\text { Univ London Imperial Coll Sci } \\
\qquad \& \text { Med }\end{array}$ & 215 & 0.3839 \\
\hline Univ New S Wales & 211 & 0.3768 \\
\hline Univ Illinois & 209 & 0.3732 \\
\hline Univ Alberta & 206 & 0.3678 \\
\hline Natl Renewable Energy Lab & 203 & 0.3625 \\
\hline
\end{tabular}

Table 9 shows the distribution of the "energy \& fuels" literature to different scientific fields. Chemical engineering and petroleum engineering appear to dominate the field contributing just below $60 \%$ of the relevant literature. Thermodynamics, mechanical engineering and electrochemistry follow contributing $15 \% ; 8.7 \%$ and $8.3 \%$ respectively to the energy and fuels literature. It can be argued that these specialities constitute the priority areas in the field of "energy and fuels" research.

Table $\mathbf{1 0}$ shows the number of publications in the "energy \& fuels" core literature from South Africa and four comparator countries - Australia, Canada, Malaysia and New Zealand during the period 2000-2005. The comparator countries are those with which South African authorities compare the country historically. South Africa produced 23.8 publications per year, similar to the number of publications produced by Malaysia. New Zealand produced 29 publications per year, Australia 157.3 publications and Canada
Table 9. Distribution of "Energy \& fuels" Publications to Scientific Fields (2000-2006)

\begin{tabular}{|c|c|c|}
\hline Subject Category & Record Count & $\%$ of 56,005 \\
\hline Engineering, Chemical & 16,829 & 30.0491 \\
\hline Engineering, Petroleum & 16,670 & 29.7652 \\
\hline Thermodynamics & 8,451 & 15.0897 \\
\hline Engineering, Mechanical & 4,883 & 8.7189 \\
\hline Electrochemistry & 4,633 & 8.2725 \\
\hline Engineering, Multidisciplinary & 4,292 & 7.6636 \\
\hline Mechanics & 2,795 & 4.9906 \\
\hline Environmental Sciences & 2,580 & 4.6067 \\
\hline $\begin{array}{l}\text { Materials science, Multidiscipli- } \\
\text { nary }\end{array}$ & 2,573 & 4.5942 \\
\hline Geosciences, Multidisciplinary & 1,928 & 3.4425 \\
\hline Chemistry, Physical & 1,877 & 3.3515 \\
\hline Agricultural Engineering & 1,791 & 3.1979 \\
\hline $\begin{array}{l}\text { Biotechnology and Applied } \\
\text { Microbiology }\end{array}$ & 1,791 & 3.1979 \\
\hline Nuclear Science \& Technology & 1,687 & 3.0122 \\
\hline Physics, Nuclear & 1,422 & 2.5391 \\
\hline $\begin{array}{l}\text { Engineering, Electrical \& Elec- } \\
\text { tronic }\end{array}$ & 1,419 & 2.5337 \\
\hline $\begin{array}{c}\text { Physics, Atomic, Molecular \& } \\
\text { Chemical }\end{array}$ & 1,388 & 2.4784 \\
\hline Environmental Studies & 1,349 & 2.4087 \\
\hline Engineering, Civil & 887 & 1.5838 \\
\hline $\begin{array}{c}\text { Construction \& Building Tech- } \\
\text { nology }\end{array}$ & 818 & 1.4606 \\
\hline Chemistry, Applied & 782 & 1.3963 \\
\hline
\end{tabular}

322.8 publications per year. Australia and Canada produce substantially larger number of energy and fuels publications than South Africa.

In order to normalize the comparison, the number of energy \& fuels publications per million population and per KWh of electricity produced are estimated. The two indicators provide evidence of the research support the population and the energy sectors receive in the various countries. The table shows that South Africa compares unfavourably with the four comparator countries in both indicators. Malaysia appears to produce almost twice as many publications per million population and three times as many publications per billion KWh produced as South Africa. South Africa should increase its energy \& fuels publications by at least an order of magnitude if it wishes to be comparable with the other countries in the table (i.e. Australia; Canada and New Zealand). 
Table 10. No. of Publications in Energy and Fuel Core Literature and Indicators

\begin{tabular}{|c|c|c|c|c|c|}
\hline Year & South Africa & Australia & Canada & Malaysia & New Zealand \\
\hline 2000 & 17 & 188 & 348 & 14 & 31 \\
\hline 2001 & 22 & 158 & 300 & 13 & 45 \\
\hline 2002 & 15 & 117 & 258 & 20 & 20 \\
\hline 2003 & 27 & 159 & 322 & 21 & 20 \\
\hline 2004 & 21 & 146 & 334 & 37 & 27 \\
\hline 2005 & 41 & 176 & 375 & 37 & 31 \\
\hline $2000-2005$ & 143 & 944 & 1937 & 142 & 174 \\
\hline Average per year (2000-05) & 23.8 & 157.3 & 322.8 & 23.6 & 29 \\
\hline Population* (millions) & 47.5 & 20.3 & 32.5 & 25.8 & 4.0 \\
\hline $\begin{array}{l}\text { Number of Publications per } \\
\text { million population }\end{array}$ & 0.5 & 7.7 & 9.9 & 0.9 & 7.2 \\
\hline $\begin{array}{l}\text { KWh Electricity Produced } \\
(2004)^{* *} \text { (billions) }\end{array}$ & 227 & 225 & 573 & 78 & 41 \\
\hline $\begin{array}{l}\text { Number of publications per } \\
\text { billion KWh produced }\end{array}$ & 0.10 & 0.70 & 0.56 & 0.30 & 0.70 \\
\hline
\end{tabular}

*Source: UN Statistics Division (http://unstats.un.org/demographic/products/indw/tab1a.htm)

**Source: International Energy Agency (2004), www.iea.org/statistics

Table 11. Emphasis on Energy and Fuels Research (1997-2007)

\begin{tabular}{|c|c|c|c|}
\hline Country & Total no. of National Publications & Energy \& fuels Publications & Ratio \\
\hline \hline SA & 52,265 & 238 & 0.45 \\
\hline Australia & 309,280 & 1,534 & 0.49 \\
\hline Canada & 512,970 & 3,293 & 0.64 \\
\hline Malaysia & 59,621 & 297 & 0.50 \\
\hline New Zealand & 12,728 & 250 & 1.90 \\
\hline
\end{tabular}

Table 11 shows the research emphasis in the field of energy \& fuels in South Africa and the four comparator countries taking into account their total research activity. The table shows the number of national publications (all scientific fields) produced by the particular countries over the period and the total number of energy \& fuels publications. The last column shows the ratios of energy \& fuels publications to the total number of national publications. South Africa again does not compare favourably with the four comparator countries but the gap is not as big as in the comparison of number of publications per million population and number of publications per billion KWh produced.

In the context of the above comparisons it should be emphasized that the absolute numbers are important as well. As discussed, the South African publications in the field of energy and fuels indicate that the country's education institutions have sub-critical number of researchers.

In the previous section it is argued that the concentration of research in South Africa is sub-critical. In order to con- firm that assertion the performance of the South African institutions with those of the comparator countries is analysed. The University of Malaya in Malaysia produced almost twice as many publications as the University of Cape Town and its national share during the period was $25 \%$ while UCT's national share was only $13 \%$. The comparison with New Zealand makes the same point. The University of Auckland produced 80 publications during the period and it had a $40 \%$ share in the country. Examination of the most prolific institutions in Australia and Canada verify our argument. The University of N.S. Wales in Australia produces more energy research articles per year (30 per year 20042006) than the South African Universities produce during the seven year period. Similarly in Canada the University of Alberta produces on average (2004-2006) 48 publications per year. South African universities do not have the critical mass required in the field of energy \& fuels.

Table 12 identifies South Africa's research emphasis in different specialties within the energy and fuels field. The table shows the share of the specific specialty (e.g. chemical 
Table 12. SA: Relative Research Priorities. Selected Fields 2000-2006

\begin{tabular}{|c|c|c|c|}
\hline Discipline & $\begin{array}{c}\text { SA: Share in } \\
\text { Field }\end{array}$ & $\begin{array}{c}\text { World: Share } \\
\text { in Field }\end{array}$ & $\begin{array}{c}\text { Activity } \\
\text { Index }\end{array}$ \\
\hline \hline $\begin{array}{c}\text { Engineering } \\
\text { Chemical }\end{array}$ & 30.2 & 30.0 & 1.0 \\
\hline $\begin{array}{c}\text { Engineering Petro- } \\
\text { leum }\end{array}$ & 7.3 & 29.8 & 0.2 \\
\hline $\begin{array}{c}\text { Thermodynamics } \\
\text { Engineering Me- } \\
\text { chanical }\end{array}$ & 21.4 & 15.1 & 1.4 \\
\hline Electrochemistry & 2.6 & 8.7 & 1.4 \\
\hline $\begin{array}{c}\text { Environmental } \\
\text { Sciences }\end{array}$ & 8.9 & 4.6 & 1.9 \\
\hline $\begin{array}{c}\text { Environmental } \\
\text { Studies }\end{array}$ & 8.9 & 2.4 & 3.7 \\
\hline Mechanics & 11.4 & 5.0 & 2.3 \\
\hline
\end{tabular}

engineering) within the field of energy \& fuels for South Africa and the World and the activity index. An activity index of one indicates that the country's research effort in the given specialty/discipline corresponds precisely to the world average; $\mathrm{AI}>1$ reflects higher than average; $\mathrm{AI}<1$ lower than average effort dedicated to the under examination field. The table shows that South Africa's attention to chemical engineering corresponds to the World's effort in the specialty; South Africa pays twice and four times as much attention on environmental sciences and environmental studies respectively as the rest of the World and it has limited focus on petroleum engineering $(\mathrm{AI}=0.2)$ and electrochemistry $(\mathrm{AI}=0.3)$.

\section{DISCUSSION AND CONCLUDING REMARKS}

This article reports for first time an assessment of the energy and fuels research in South Africa. Even though research assessment is considered the cornerstone of science and technology policy in South Africa the energy field has not been examined in the past.

Scarcity of energy research assessments is an international phenomenon. A brief search of the international literature identifies a limited number of such attempts in the open literature. Probably the main reason for the identified scarcity is the difficulty in describing and delineating the field. Energy research is not a coherent and well defined field of research.

For this effort, scientometrics are uilised in order to map and assess the field of energy research in South Africa.

It was identified that the ISI databases are the appropriate information platform for the assessment of energy research in South Africa. For this investigation the articles appeared in the 62 journals in the field of "energy \& fuels" during the 10 year period 1997- 2007 were analysed. The major findings are as follows.

The South African National Research System is producing a relatively small number of research publications in the international energy core literature. Energy research literature constitutes $0.45 \%$ of the national effort. This is a relatively small share in comparison with the country's top disciplines (i.e. medicine $(6.04 \%)$, plant sciences $(5.07 \%)$, ecology $(3.50 \%))$. It is suggested that the revealed priority areas of research are those which have institutionalize their funding. The recent institutionalization of funding of energy research through the South African Energy Research Institute (SANERI) has the potentials to transform energy research in one of the country's priority fields. It can be argued that such an action is a necessity as the country's Government has decided to become a major player in the field of research by supporting and developing the pebble bed modular reactor technology. PBMR receives six billion Rands over a period of three years. The effort will face considerable constraints if the higher education sector does not increase its research and human resources outputs in the field.

The number of the South African energy research publications is in an increasing trend albeit from a small basis.

Research specialities emphasised in the country's energy research are: chemical engineering and thermodynamics. Mechanics and mechanical engineering follow.

The universities of Cape Town and Pretoria are the most prolific energy research producers sharing the top position contributing $11.76 \%$ of the relevant literature each (28 publications). SASOL, Rand Afrikaans University and University of Stellenbosch follow with above $10 \%$ contributions during the period. It is emphasised that the small number of publications produced makes the stability of the comparison over time sensitive to the movement of researchers from one institution to another. For example, the move of one or two prolific researchers from one institution to another could drastically change the rankings of the institutions producing energy research. Comparisons with universities abroad indicate that the South African Universities should aim to increase 5 to 10 fold their energy publications (and consequently their number of researchers in the field) if they wish to be comparable with similar institutions abroad. The Department of Science and Technology has initiated recently the research chairs program. Universities apply in competition with each other for the establishment of research chairs -valued at two million Rands per year for periods five to ten years - in scientific fields of their choice. In the applications, universities have to nominate quality researchers in the particular fields to occupy the chairs. The minimum number of researchers in the energy field means that universities will not be able to identify easily relevant researchers and hence the field will not be supported by this policy instrument. A possible way to mitigate this concern will be for SANERI and the Department of Science and Technology to earmark an appropriate number of chairs for fields of national priority like the one on energy.

The top five most prolific institutions in the country participate in the production of just above $50 \%$ of the country's contribution to core energy \& fuels literature. This is considered a high dispersion as a number of other scientific disciplines in the country are concentrated in one or two institutions. It is suggested that political equity considerations in the country spill-over in the research domain as well. The issue is identified as being of particular developmental and 
science policy importance. Can a country leap-frog its science and innovation system to catch up the rest of the world and compete internationally through a "distributed" approach or it should concentrate its limited scientific expertise to a limited, focused research centres? The issue has also been identified as one of the major South African policy challenges in the recent OECD [26] review of the country's innovation policy.

Analysis of the specialization patterns of energy research at the country's top universities reveals that different institutions emphasize different specialties. At UCT emphasis is on environmental issues of energy; at the University of Pretoria on chemical engineering and thermodynamics; at Rand Afrikaans University on material sciences-multidisciplinary and at the University of Stellenbosch on mechanical engineering.

Identification of the main countries collaborating with South Africa in the field of research shows that USA is the country's main collaborating partner. Collaboration takes place mainly in the fields of environmental sciences, environmental studies and electrical and electronic engineering.

In the international context, South Africa compares unfavourably with the four comparator countries- Australia, Canada, Malaysia and New Zealand- in both indicators developed - number of energy \& fuels publications per million population and number of publications per KWh of electricity produced. It is suggested that South Africa should increase its energy \& fuels publications by at least an order of magnitude if it wishes to be comparable with the other countries.

Estimation of the activity indices of the most active scientific disciplines contributing to energy and fuels research in the country shows that: South Africa's attention to chemical engineering corresponds to the World's effort in the specialty; South Africa pays twice and four times as much attention as the rest of the World on environmental sciences and environmental studies respectively and it has limited focus on petroleum engineering $(\mathrm{AI}=0.2)$ and electrochemistry $(\mathrm{AI}=0.3)$. It is debatable whether the identified make up supports the country's developmental requirements.

\section{ACKNOWLEDGEMENT}

The author wishes to thank Drs Kostoff RN. and Schubert A. for provision of information, and SANERI for financial support. The usual caveat applies.

\section{REFERENCES}

[1] NACI, The South African National System of Innovation: Structures. Policies and Performance - Background Report to the OECD Country Review of South Africa's National System of Innovation. National Advisory Council on Innovation, Pretoria, 2006.

[2] M. Molatudi, and A. Pouris, "Assessing the Knowledge Base for Biotechnology in South Africa: A Bibliometric Analysis of South African Microbiology and Molecular Biology and Genetics Research", Scientometrics, vol. 68(1), pp. 97-108, 2006.
[3] ASSAf. Report on Strategic Approach to Research Publishing in South Africa, Academy of Sciences of South Africa, Pretoria, 2006.

[4] A. Pouris, "The International Performance of the South African Academic Institutions: A Citation Assessment", Higher Education: The International Journal of Higher Education and Educational Planning, vol. 54 (4), pp. 501-509, 2007.

[5] R. Rojo, and I. Gomez, "Analysis of the Spanish scientific and technological output in the ICT sector", Scientometrics, vol. 66 (1), pp. 101-121, 2005.

[6] P.G. Dastida, and S. Ramachandran, "Engineering research in ocean sector: An international profile", Scientometrics, vol. 65 (2), pp. 199-213, 2005 .

[7] J. Schummer, "Multidisciplinarity, interdisciplinarity and patterns of research collaboration in Nanoscience and Nanotechnology", Scientometrics, vol. 59(3), pp. 425-465, 2004.

[8] I.K. Ravichandra Rao, and P.M.S. Suma, "A quantitative study of Indian Engineering Literature", Scientometrics, 46 (3), pp. 605619, 1999.

[9] World Bank. Monitoring and Evaluation. International Bank for Reconstruction and Development, World Bank Washington, D.C., 2004.

[10] L. Georgiou, "Assessing the Framework Programmes - A Metaevaluation”, Evaluation, vol. 1(2), pp. 171-188, 1995.

[11] D. De Solla Price, The Productivity of Research Scientists. In Yearbook of Science and the Future, Encyclopaedia Britannica Inc., University of Chicago, Chicago, 1975.

[12] R.J.W. Tijssen, “A Quantitative Assessment of Interdisciplinary Structures in Science and Technology: Co Classification Analysis of Energy Research", Res. Policy, vol. 21(1), pp. 27-44, 1992.

[13] B.M. Gupta, A citation analysis of internal and external connections of a research branch: A case study of solar energy research in the USSR, Annals of Library Science and Documentation, vol. 27(14), 1980.

[14] J. Lawson, B. Kostrewsi, and C. Oppenheim. "A Bibliometric study on a new subject field: energy analysis", Scientometrics, vol 2(3), pp. 227-237, 1980.

[15] J. Vlachy, 'World Publication Output in Cross Disciplinary Physics: Materials Science, Physical Chemistry, Energy Research, Biophysics," Czechoslovak Journal of Physics vol. B33, 1983.

[16] S.M.A. Ibrahim, "The Use of Matrices for the Determination of Science and Technology Priority Areas for the Achievement of Energy Goals in Egypt", Energy Res., vol. (8), pp. 247-262, 1984.

[17] A. Pouris and A. Pouris, "Structure of Energy Related Literature: An Application of Citation Analysis. South African J. Sci., vol. 83, pp. 138-142, 1987.

[18] Ibid 12.

[19] T.N. Vanleeuven, and R.J.W. Tijssen, "Assessing Multidisciplinary Areas of Science and Technology A Synthetic Bibliometric Study of Dutch Nuclear Energy Research”, Scientometrics, vol. 26 (1), pp. 115-133, 1993.

[20] A. Uzun, "National patterns of research output and priorities in renewable energy", Energy Policy, vol. 30 (2), pp. 131-136, 2002.

[21] R.N. Kostoff, R. Tshiteya, K.M. Pfeil, J.A. Humenik, and G. Karypis, "Power Source Roadmaps Using Database Tomography and Bibliometrics", Energy, vol. 30(5), pp. 709-730, 2005.

[22] S.C. Bradford, Documentation. Washington D.C: Public Affairs Press, 1950.

[23] E. Garfield, "The Significant Scientific Literature Appears in a Small Core of Journals", Scientist, vol. 10(17), p. 13 Sept. 2, 1996.

[24] E. Garfield. "Bradford's Law and related statistical patterns", in Essays of an Information Scientist. vol. 4, pp. 476, ISI Press, Philadelphia, 1981.

[25] A. Pouris, "Nanoscale Research in South Africa: A Mapping Exercise Based on Scientometrics", Scientometrics, vol. 70 (3), pp. 541553, 2007.

[26] OECD. Review of the South Africa's Innovation Policy, DSTI/STP 12, Organisation for Economic Cooperation and Development, Salle des Nations, La Défense, Paris, 2007. 